\title{
Annealing Effect of Temperature on the Optical Properties of Nanostructure CdS Films
}

\author{
Awodugba A.O, Adedokun.O and Sanusi Y.K \\ Department of Pure and Applied Physics, Ladoke Akintola University of Technology, P.M.B 4000, Ogbomoso, \\ Nigeria. \\ Address correspondence to Adedokun Oluwaseun, Department of Pure and Applied Physics, Ladoke Akintola \\ University of Technology, P.M.B 4000, Ogbomoso, Nigeria.
}

\begin{abstract}
Cadmium Sulfide polycrystalline thin films were deposited on glass substrates using chemical bath technique at deposition temperature of $60^{\circ} \mathrm{C}$ from a bath containing cadmium chloride, ammonium chloride, ammonium hydroxide and thiourea. The structure and the crystallite size of these films were studied by X-ray diffraction. The optical properties: absorption, transmission, reflection, band gap, absorption coefficient, extinction coefficient and refractive index as a function of annealed temperature were measured. The influence of thermal treatment under various annealing temperature on the optical properties for some deposited films were studied and discussed.
\end{abstract}

Keywords: Annealed temperature, as-grown, CdS films, chemical bath technique, optical properties

\section{Introduction}

Nowadays, the products of semiconductor industry spread all over the world and deeply penetrate into a daily life of human being. Thin films are well known for their applications in many physical based industries as instruments for many semiconductor devices [1]. In recent years, interest in the physical properties of thin films has considerably increased because new effects can appear in the film states that are not observed in the bulk samples [2].

Thin film of cadmium sulfide is a suitable n-type semiconductor for a window layer in $\mathrm{CdTe} / \mathrm{CdSheterojunction} \mathrm{solar} \mathrm{cells}[3,4] . \mathrm{CdS}$ is an important material due to its novel properties like photoconductivity, high index of refraction (2.5) and its high electron affinity [5, 6].

Several techniques like vacuum evaporation, sputtering, electro-deposition, radio frequency, pulsed laser evaporation, molecular beam epitaxy (MBE), metal vapour organic deposition (MOCVD), spray pyrolysis deposition (SPD), close spaced sublimation (CSS), successive ionic layer adsorption and reaction (SILAR), Micelle method and chemical bath deposition (CBD) are being used to develop CdS thin films. Among these techniques, CBD has become an attractive technique due to its simplicity, low-cost and having large surface area deposition at low temperature [7].

It has been reported that this technique has been offering an excellent control to deposit uniform thin films and also enhances the performance of $\mathrm{CdS}$ window layer as compared to other film growing techniques [8].

The preparation of CdS through CBD involves immersion of the substrate (glass in this case) in a bath of alkaline aqueous solution containing $\mathrm{Cd}^{2+}$ and $\mathrm{S}^{2-}$ resulting from the chemical reaction in the solution to grow CdS film on the immersed substrate [9]. The control of deposition temperature, concentrations of the constituent solution which provide $\mathrm{Cd}^{2+}$ and $\mathrm{S}^{2-}$ ions for chemical reaction, film deposition time, and $\mathrm{pH}$ of aqueous solution is required for the deposition of CdS film on the immersed substrate in the chemical bath technique.

$\mathrm{CdS}$ film is developed through a series of chemical reaction. Hydrolysis of cadmium salt to provide free $\mathrm{Cd}^{2+}$ ions which then react with ammonium salt to form the cadmium tetra-amine complex;

$\mathrm{Cd}^{2+}+4 \mathrm{NH}_{3} \leftrightarrows \mathrm{Cd}\left(\mathrm{NH}_{3}\right)_{4}^{2+}$

Hydrolysis radical $(\mathrm{OH})^{-1}$ also promotes the thiourea hydrolysis to release the sulphur ions through successive chemical reactions

$\mathrm{Cs}\left(\mathrm{NH}_{2}\right)_{2}+\mathrm{OH}^{-} \leftrightarrows \mathrm{S}^{2-}+\mathrm{H}_{2} \mathrm{O}$

$C d^{2+}+S^{2-} \leftrightarrows C d S_{(s)}$

Hence the presence of the free ions of $\mathrm{Cd}^{2+}$ and $\mathrm{S}^{2-}$ enables $\mathrm{CdS}$ to be formed.

The essence of this research is to investigate the effect of annealing temperature on the optical properties of $\mathrm{CdS}$ 
thin film deposited by chemical bath technique.

\section{Experimental Details}

CdS thin films were grown on microscopic glass slides substrates $(25.4 \mathrm{~mm} \times 76.2 \mathrm{~mm} \times 1.0 \mathrm{~mm})$ by CBD technique. Cadmium chloride and thiourea were used as precursor sources of $\mathrm{Cd}^{2+}$ and $\mathrm{S}^{2-}$ respectively. Ammonium hydroxide and ammonium chloride were also used as complexing agent and $\mathrm{pH}$ control respectively.

The deposition temperature and time were $60^{\circ} \mathrm{C}$ and 60 minutes respectively. Details of the deposition processes were reported in recent past work [10]. The structure of the film with thickness of $3.69 \mathrm{~nm}$ was obtained using X-ray diffraction, XRD (Radicon MD 10 mini diffractometer, with $\mathrm{Cu}$-k $\alpha$ radiation).

The optical absorption and transmission studies of the film in the wavelength range $300-1100 \mathrm{~nm}$ were examined using spectrophotometer (model UV-6405, Genway). The thickness was determined by the gravimetric method using Mettler Toledo (PB303) analytical balance. The effect of annealing temperatures of the sample at $70^{\circ} \mathrm{C}$, $140^{\circ} \mathrm{C}$ and $210^{\circ} \mathrm{C}$ for 1 hour under vacuum oven has been investigated.

\section{Results and Discussion}

Figure 1 shows the x-ray diffraction pattern of the as-grown CdS thin film. The pulses (in arbitrary unit)

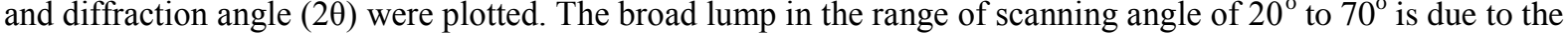
amorphous glass substrate. The planes (001), (002), (042), (107) and (004) indicate the covellite phase with hexagonal crystal structure. It has also been observed that the CdS films are polycrystalline with orientation along different planes and phases. The grain size of as-grown $\mathrm{CdS}$ film was evaluated to be between $12.9 \mathrm{~nm}$ to $15.4 \mathrm{~nm}$ by using the Debye Scherrer's formula.

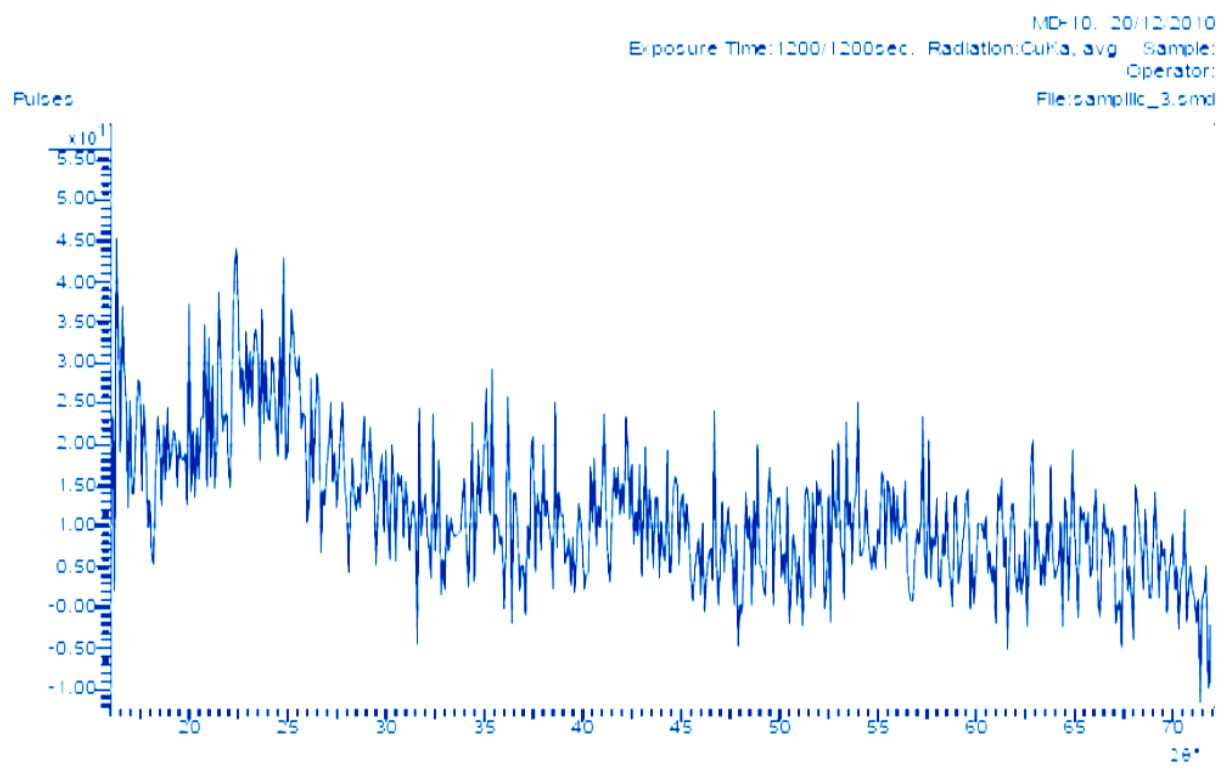

Figure 1: XRD pattern for the as-grown CdS film

In Fig. 2, the absorbance versus wavelength is plotted for CBD-CdS; as-grown and annealed thin films. From the absorbance spectra, it is observed generally that the absorbance of the films decrease with increasing wavelength and absorbance of the film is mainly in the VIS region of the solar radiation spectrum. The sharp absorption edges occurred at wavelength less than 530nm and the absorption edge of the film slightly shift towards longer wavelength with increasing annealing temperature. The highest absorbance values are observed from the annealed samples with the critical annealed temperature for optimum absorbance at $140^{\circ} \mathrm{C}$. Similar behaviour was noted by Elmas et al. and Abbas et al. [11, 12]. 


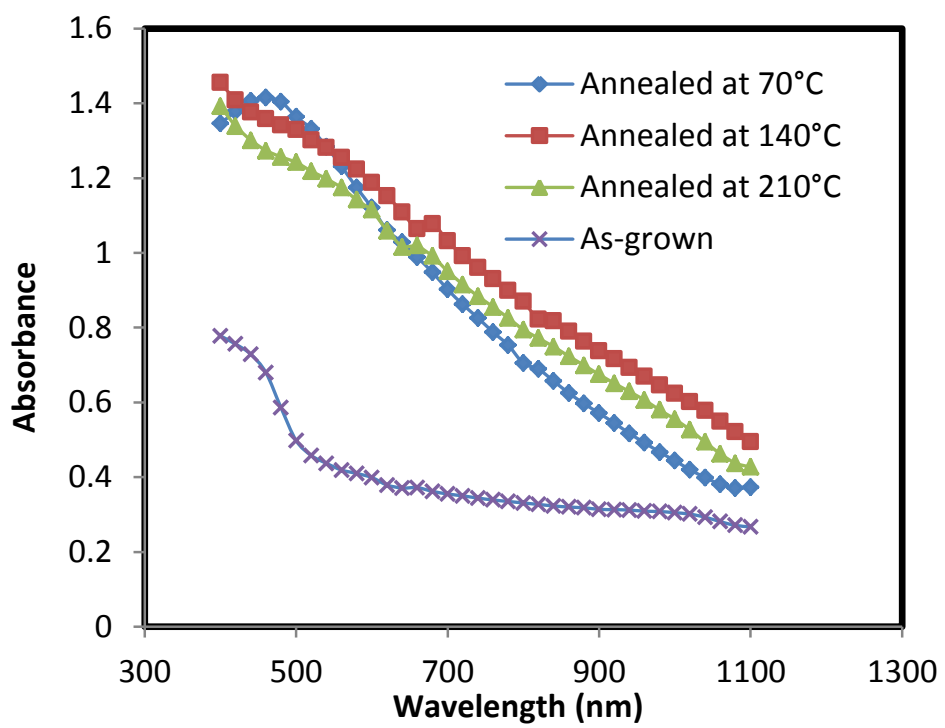

Figure 2: Absorbance as function of wavelength for CdS films at different annealing temperature

The transmission spectra of CdS film of as-grown and annealed films at $70^{\circ} \mathrm{C}, 140^{\circ} \mathrm{C}$ and $210^{\circ} \mathrm{C}$ is displayed in Fig. 3. From the transmission spectra, it is observed that the film samples transmit slightly low within UV-VIS regions but moderately high NIR regions for the as-grown films. The minimum transmittance for the films occurred within the UV region from where the transmittance increases with the wavelength towards the NIR region. The transmission spectra also showed that the films annealed at $70^{\circ} \mathrm{C}, 140^{\circ} \mathrm{C}$ and $210^{\circ} \mathrm{C}$ have transmittances greater than $25 \%$ in the VIS-NIR regions. The as-grown film showed transmittance of less than $60 \%$ within the VIS-NIR regions. However the as-grown and annealed films show transmittance that increased exponentially from the UV region towards the NIR region.

It is also observed from the Fig. 3 that increasing thermal annealing tends to reduce transmittance in all the spectrum of solar light energy. This is as a result of formation of denser films because of water evaporation. This behaviour goes in line with result published by Ezema et al. [13].

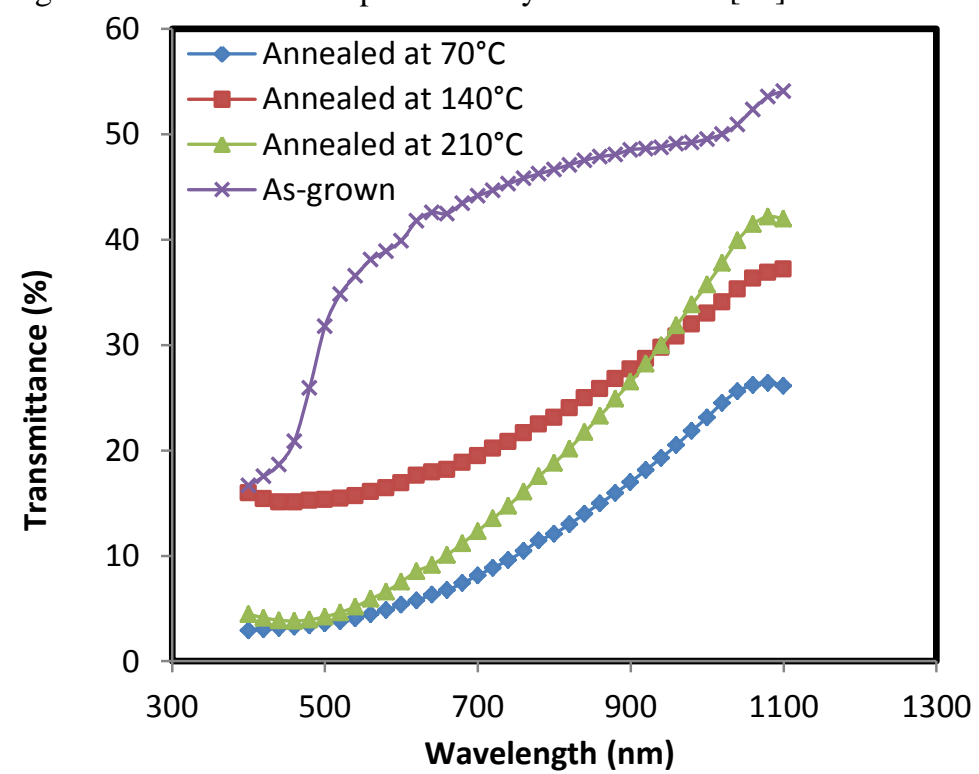

Figure 3: Transmittance as a function of wavelength for CdS films at different annealing temperature

The plots of the refraction index as a function of photon energy are shown in Fig. 4 for as-grown and annealed films. The as deposited film showed a small increase in refractive index up to NIR region before it started decreasing. More also the refractive index of the annealed film decreased uniformly to a maximum value at about $1.83 \mathrm{eV}, 1.38 \mathrm{eV}$ and $1.63 \mathrm{eV}$ for $70^{\circ} \mathrm{C}, 140^{\circ} \mathrm{C}$ and $210^{\circ} \mathrm{C}$ respectively. This is corresponding to the VIS region of the solar spectrum. However beyond this point, there is increase in the value of refractive index for annealed samples up to NIR region. The highest observed refractive index of 8.26 was observed at photon energy of $3.11 \mathrm{eV}$ for the film annealed in air at $140^{\circ} \mathrm{C}$. This trend in the behaviour of refractive index with 
annealing temperature has also been observed and was attributed to denser films arising from evaporation of water molecules off the films [14].

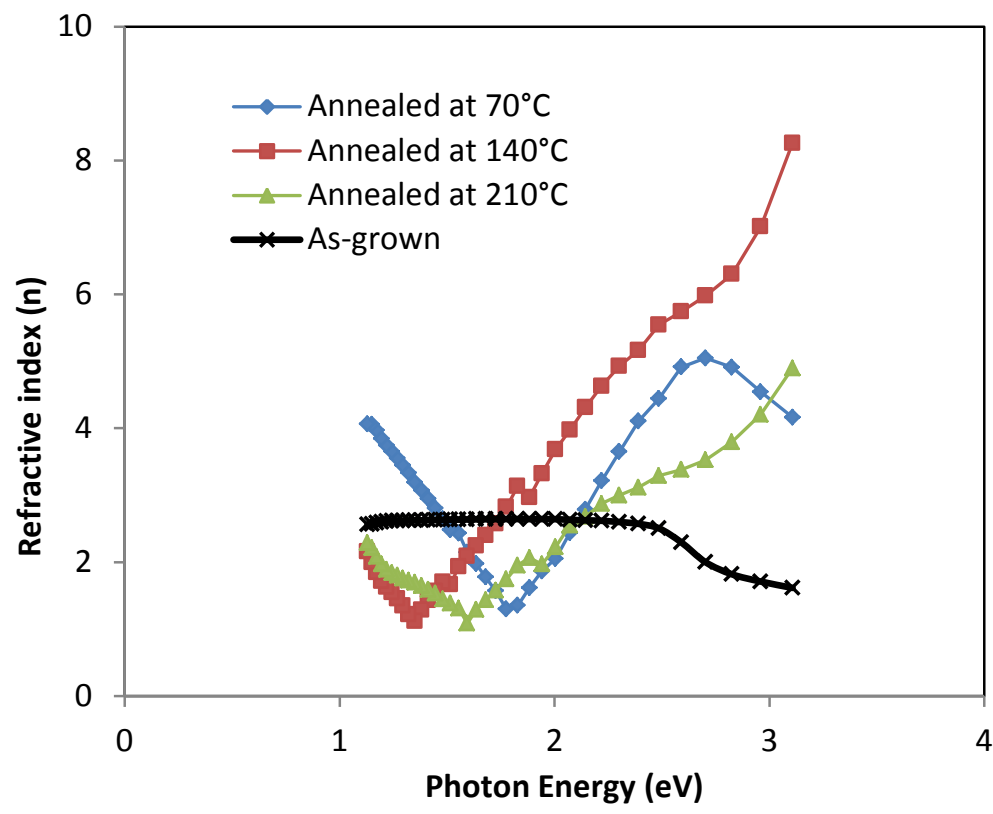

Figure 4: Plots of the refraction index as a function of photon energy at different annealing temperature

The theory of interband absorption shows that at optical absorption edge, the absorption coefficient $\alpha$ varies with the photon energy hv according to Awodugba et al. [10]. CdS is a typical direct band gap semiconductor. The absorption coefficient for direct band gap material is given by $(\alpha h v)^{2}=A\left(h v-E_{g}\right)$ [15] where $\alpha$ is the absorption coefficient, A is a constant, hv is the photon energy and Eg the band gap.

The energy band gap was determined by plotting $(\alpha h v)^{2}$ versus ho whose intercept on the energy axis gives the energy band gap $\mathrm{E}_{\mathrm{g}}$ as shown in Fig. 5. The optical band gap for as-grown and annealed film $70^{\circ} \mathrm{C}, 140^{\circ} \mathrm{C}$ and $210^{\circ} \mathrm{C}$ are $2.34 \mathrm{eV}, 1.95 \mathrm{eV}, 1.85 \mathrm{eV}$ and $1.65 \mathrm{eV}$ respectively. This shows that the energy gap decreases with increasing annealing temperature. This trend is possibly due to the evaporation of water molecules off the film and reorganization of the films [13]. The reorganization of the film particles and self-oxidation are the temperature dependence parameters that affect the band gap. These values of band gap obtained are in close agreement to the previous studies by Ezema et al., Cetinnorgu et al. and Devi et al. [13, 16, 17].

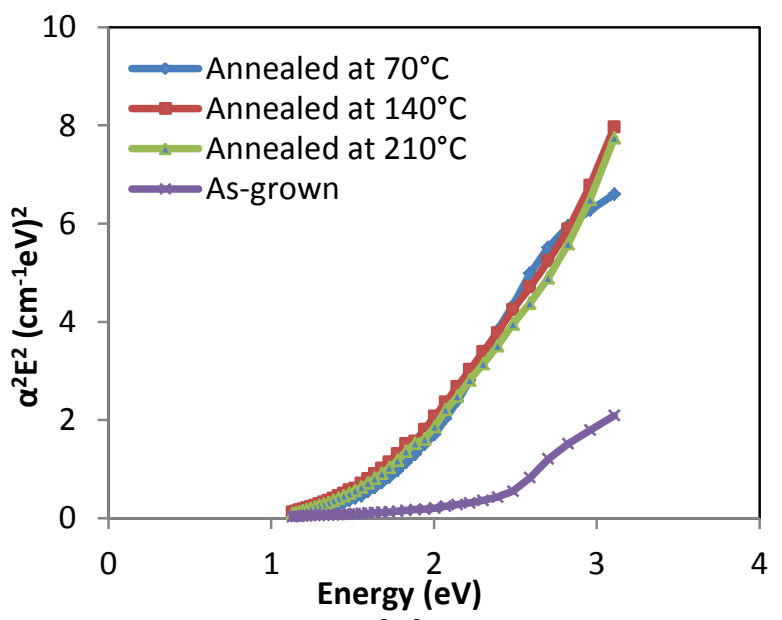

Figure 5: Plot of $\alpha^{2} E^{2}$ against Photon Energy for CdS films

Fig. 6 shows the plot of the reflectance as a function of wavelength for as-grown films and annealed at $70^{\circ} \mathrm{C}, 140^{\circ} \mathrm{C}$ and $210^{\circ} \mathrm{C}$. For as-grown film, the reflectance is increasing in the wavelength range of $400-550 \mathrm{~nm}$ and a gradual fall in the reflectance in the wavelength range of $600-1100 \mathrm{~nm}$ was observed. But however in 
annealed samples of $70^{\circ} \mathrm{C}, 140^{\circ} \mathrm{C}$ and $210^{\circ} \mathrm{C}$, the reflectance decreases with increasing wavelength toward VISNIR regions until a total sharp fall of reflectance value is reached then a sudden rise in reflectance is observed.

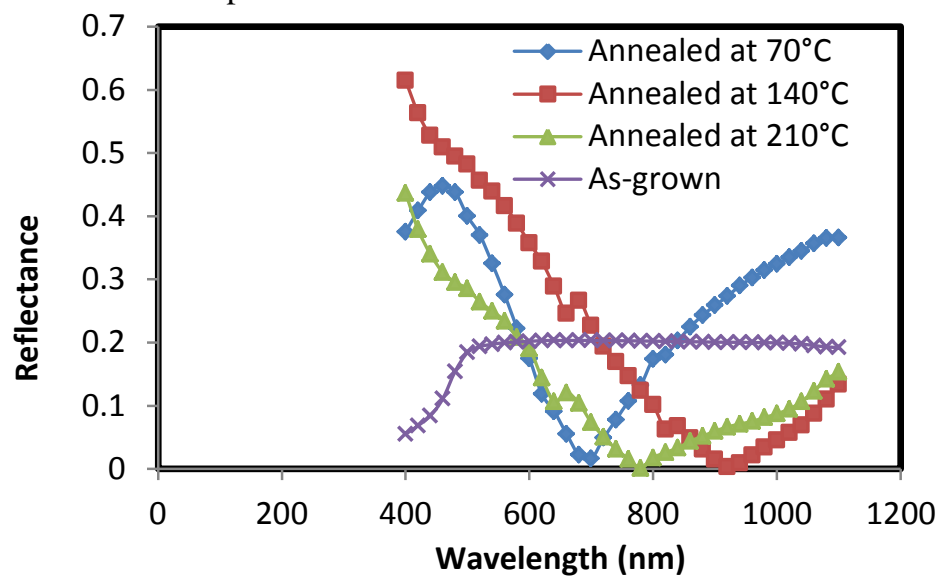

Figure 6: Graph of reflectance against wavelength of CdS thin films

The plots of absorption coefficient against photon energy are shown in Fig. 7. The spectra depict a sharp absorption edge, which are the characteristics of the crystalline state of the film. From the Fig. 7, it is also observed that absorption coefficient increases with annealing temperature. The coefficient of absorption $(\alpha)$ is related to coefficient of extinction (k) by $\alpha=\frac{4 \pi k}{\lambda}[18]$ where $\lambda$ is the wavelength of the electromagnetic wave.

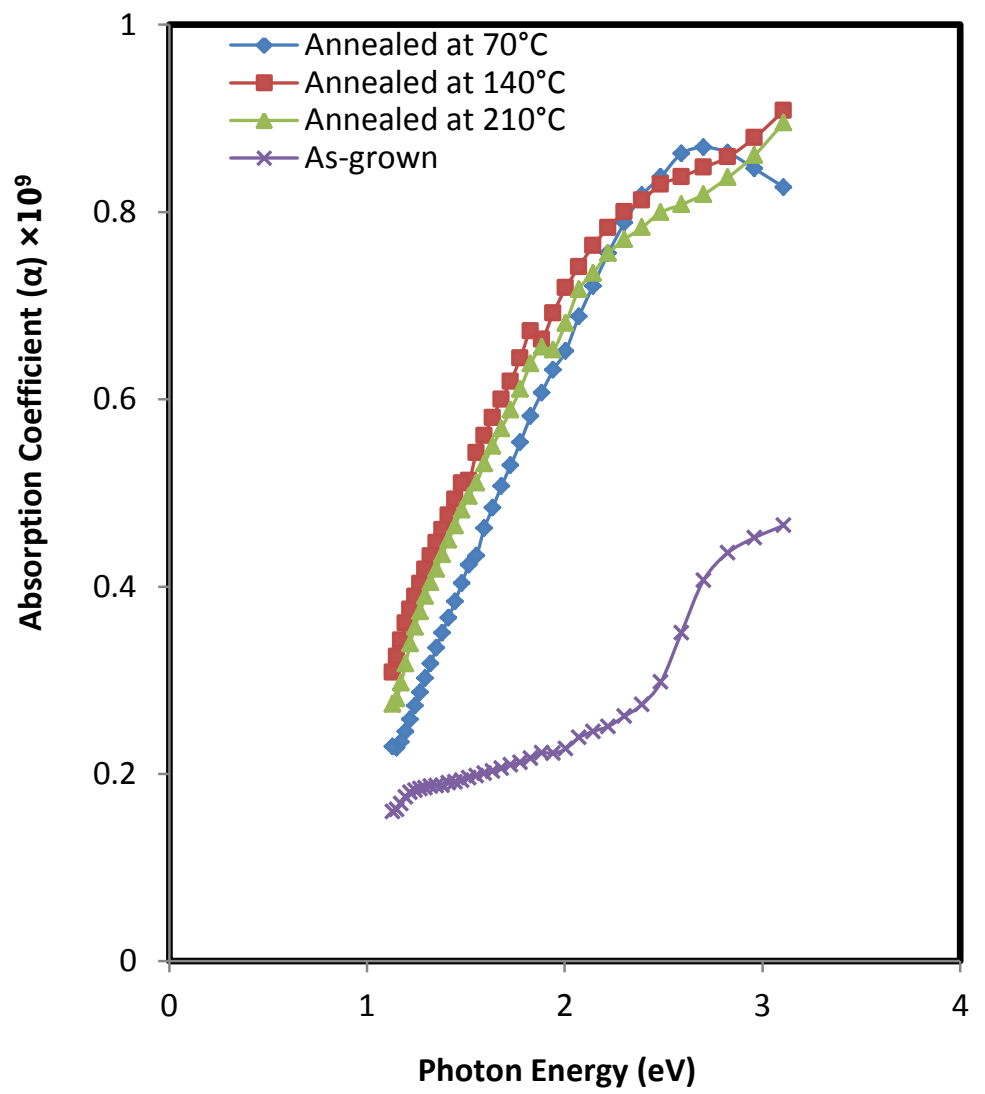

Figure 7: Variation of Absorption Coefficient against Photon Energy for CdS Thin Films

Fig. 8 displays extinction coefficient $(\mathrm{k})$ as a function of photon energy $(\mathrm{E})$. It is observed that annealed film has higher extinction coefficient than as-grown film. The maximum value of $\mathrm{k}$ value was observed at $600 \mathrm{~nm}$ of wavelength. 


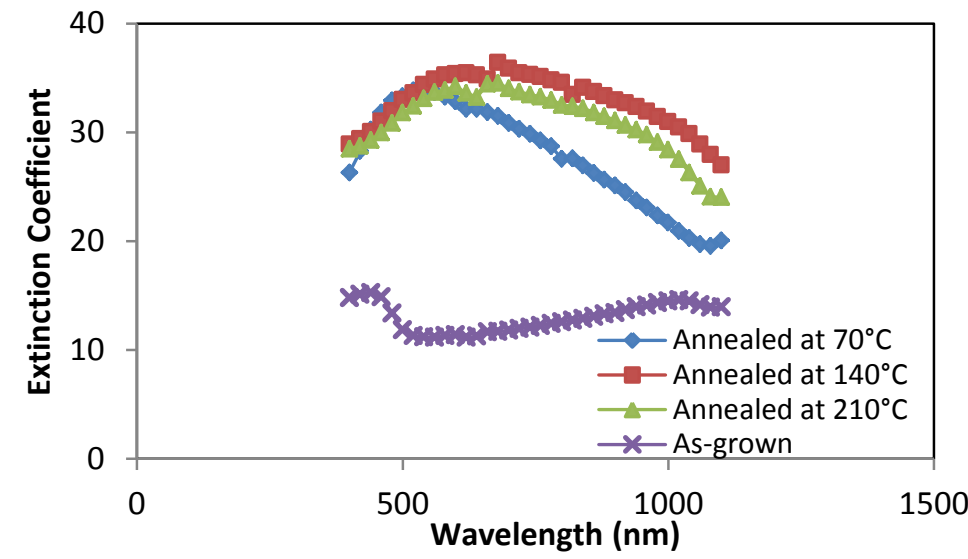

Figure 8: Variation of Extinction Coefficient against Wavelengths for CdS Films

\section{Conclusion}

Thin films of CdS were deposited successfully using chemical bath deposition techniques. The effect of annealing temperature on the optical properties of the film has been investigated.

XRD studies of as-grown CdS thin films have a covellite phase with hexagonal crystal structure. The grain size of as-grown film was found to be between $12.9 \mathrm{~nm}$ to $15.4 \mathrm{~nm}$. It was shown that thermal annealing tends to reduce transmittance and increase absorbance in all the spectrum of solar light energy. It was also observed that the energy gap decreases with increasing annealing temperature.

This study confirmed that thermal treatment strongly influence the optical properties of CdS thin films.

\section{Acknowledgements}

One of the authors wishes to acknowledge the research grant by the Faculty of Pure and Applied Sciences of the Ladoke Akintola University of Technology.

\section{References}

[1] F.I Ezema, C.E Okeke. "Chemical Bath Deposition of Beryllium Sulphide Thin Film and Its Applications" Academic Open Internet Journal, vol.9, 2003, www.acadjournal.com

[2] C.D Lokhande, A.U Ubale, P.S Pastil. Thin Solid Films 1, 1997, 302

[3] H. Metin, F. Sat, S. Erat and M. Ari. Cadmium Sulphide Thin Films Grown by CBD: The Effect of Thermal Annealing on the Structural, Electrical and Optical Properties, Journal of Optoelectronics and Advanced Materials", 10 (10), $2008,2622-2630$.

[4] F. Kadirgan, D. Mao, W. Song, T. Ohno, and B. McCandless. "Properties of Electrodeposited Cadmium Sulfide Films for Photovoltaic Devices with Comparison to CdS Films prepared by Other Methods" Turk J. Chem. 24, 2000, $21-33$.

[5] T.L. Chu, S.S. Chu, C. Ferekides, C.Q. Wu, J. Britt, C. Wang. High efficiency thin Film CdS/CdTe heterojunction solar cells, J. Cryst. Growth, 117 (1-4), 1999, p. 1073.

[6] C. Ferekides, J. Britt. CdTe solar cells with efficiencies over 15\%, J. Sol. Ener. Mat. Sol. C., 35, 1994, pp.255-262.

[7] X.Wu , J. Keane, R. Dhere, D. Dehart, D. Albin, A. Duda, T. Gessert, S. Asher, D. Levi, and P. Sheldon. Proceedings of the 17th European Photovoltaic Solar Energy Conference. Munich, German, October 22-26, 2001, 995.

[8] Z. Rizwan, B. Z. Azmi, M. G. M. Sabri. Effect of Annealing Temperature on the Optical Properties of Nanostructured CdS films prepared by Chemical Bath Deposition Technique, Optoelectronics and Advanced Material-Rapid Communication Vol.5, 4, 2011, p. $393-397$.

[9] M. Froment, D. Lincot. Phase Formation processes in solution at the atomic level: Metal chalcogenide semiconductors, Electrochim Acta 40, 1995, 1293-1303.

[10] A.O. Awodugba, and O. Adedokun. "On the Physical and Optical Characteristics of CdS Thin Films Deposited by the Chemical Bath Deposition Technique" Pacific Journal of Science and Technology 12(2), 2011, 334-341.

[11] S. Elmas, S. Ozcan, S. Ozder and V. Bilgin. Influence of Annealing Temperature on the Electrical and Optical Properties of CdS Thin Films, ActaPhysicaPolonica A,121 (1), 2012, 56-58.

[12] M.M Abbas, A. Ab-M Shehab, N-A. Hassan, A-K. Al-Samuraee, Effect of temperature and deposition time on the optical properties of chemically deposited nanostructure PbS thin films, Thin Solid Films 519,2011, 4917-4922.

[13] Ezema F.I, S.C. Ezugwu, R.U. Osuji, P.U. Asogwa, B.A. Ezekoye, A.B.C. Ekwealor, and M.P. Ogbu. "Role of Thermal Annealing on the Optical and Solid State Properties of Chemically Deposited Cadmium Sulphide Nanocrystalline Thin Film Grown in a Polymer Matrix, Journal of Non-Oxide Glasses. 1(1), 2010, 45-50.

[14] D. Soubane, A. Ihlal and G. Nouet. The Role Of Cadmium Oxide Within The Thin Films of the Buffer Cds Aimed At Solar Cells Based Upon CIGS Films Fabrication, M.J. Condensed Matter, 9, 2007, 1.

[15] J. Tauc. Amorphous and Liquid Semiconductors (Plenum Press, London and New York, 1974)

[16] E. Cetinorgu, C. Gumus and R. Esen. Effects of Deposition Time on the Optical Properties of Air-Annealed Chemical Bath Deposited CdS Films, Thin Solid Films, 515 (4), 2006, 1688-1693.

[17] R. Devi, P. Purkayastha, P.K. Kalita and B. K. Sarma. Synthesis of nanocrystalline CdS thin films in PVA matrix,Bull. Mater. Sc. 30,2007, 123-128

[18] D.E Gray. (Ed.)American Institute of Physics Handbook(3rd Edition McGraw-Hill: New York, NY1982). 